Pulsed Laser Surface Hardening of Ferrous Alloys

Zhiyue Xu, 1 Claude B. Reed1, Keng H. Leong2 and Boyd V. Hunter 3

1 Technology Development Division, Argonne National Laboratory, 9700 S. Cass Avenue, Building 360, Argonne, IL 60439

2 Applied Research Laboratory, The Pennsylvania State University State College, PA 16804

3 LightPath Technologies, Inc., 6820 Academy Parkway East, NE Albuquerque, NM 87109

Submitted for publication in the

Proceedings of the International Conference on Applications of Lasers and Electro-Optics (ICALEO'99)

San Diego, California

November 15-18, 1999

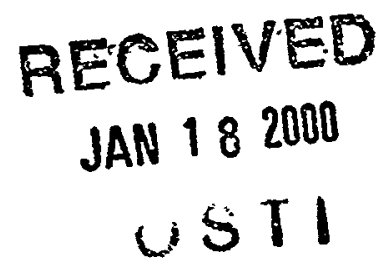

The submitted manuscript has been authored by a contractor of U.S. Government under contract

No. W - 31 - 109-ENG-38. Accordingly, the U.S. Government retains for nonexclusive, royalty-free license to publish or reproduce the published form of this contribution, or allow others to do so, for U.S. Government purposes. 


\section{DISCLAIMER}

This report was prepared as an account of work sponsored by an agency of the United States Government. Neither the United States Government nor any, agency thereof, nor any of their employees, make any warranty, express or implied, or assumes any legal liability or responsibility for the accuracy, completeness, or usefulness of any information, apparatus, product, or process disclosed, or represents that its use would not infringe privately owned rights. Reference herein to any specific commercial product, process, or service by trade name, trademark, manufacturer, or otherwise does not necessarily constitute or imply its endorsement, recommendation, or favoring by the United States Government or any agency thereof. The views and opinions of authors expressed herein do not necessarily state or reflect those of the United States Government or any agency thereof. 


\section{DISCLAIMER}

Portions of this document may be illegible in electronic image products. Images are produced from the best available original document. 


\title{
Pulsed Laser Surface Hardening of Ferrous Alloys
}

\author{
Zhiyue Xu, 1 Claude B. Reed1, Keng H. Leong2 and Boyd V. Hunter ${ }^{3}$ \\ 1 Technology Development Division, Argonne National Laboratory, \\ 9700 S. Cass Avenue, Building 360, Argonne, II 60439 \\ 2 Applied Research Laboratory, The Pennsylvania State University \\ State College, PA 16804 \\ ${ }^{3}$ LightPath Technologies, Inc., 6820 Academy Parkway East, NE \\ Albuquerque, NM 87109
}

\begin{abstract}
A high power pulsed Nd:YAG laser and special optics were used to produce surface hardening on 1045 steel and gray cast iron by varying the process parameters. Unlike $\mathrm{CO}_{2}$ lasers, where absorptive coatings are required, the higher absorptivity of ferrous alloys at the Nd:YAG laser wavelength eliminates the necessity of applying a coating before processing. Metallurgical analysis of the treated tracks showed that very fine and hard martensitic microstructure (1045 steel) or inhomogeneous martensite (gray cast iron) were obtained without surface melting, giving maximum hardness of HRC 61 and HRC 40 for 1045 steel and gray cast iron respectively. The corresponding maximum case depths for both alloys at the above hardness are $0.6 \mathrm{~mm}$. Gray cast iron was more difficult to harden without surface melting because of its lower melting temperature and a significantly longer time-at-temperature required to diffuse carbon atoms from the graphite flakes into the austenite matrix during laser heating. The thermal distortion was characterized in term of flatness changes after surface hardening.
\end{abstract}

\section{INTRODUCTION}

Transformation surface hardening, selective austenitization and martensitation of local surface region of previously toughened material by rapid heating and cooling, is widely applied to many moving components such as cam or ring gears that must have a very hard surface to resist wear, along with a tough interior to resist the impact that occurs during operation. The conventional methods used to harden the surface of the ferrous materials include flame and induction hardening. Case hardened depths of several millimeters are obtained but with significant thermal distortion of the components such that rework is usually required.[1,2] Laser transformation surface hardening is an alternative technique that selectively hardens the wear surface only with the rest of the component providing the heat sink. This self-quenching eliminates the need to use oil or water quenching baths. Most attractively, laser surface hardening generates rare thermal distortion so refinishing of the part can be eliminated.

Both high power $\mathrm{CO}_{2}$ and $\mathrm{Nd:YAG}$ laser have been used to carry out surface hardening of ferrous alloys. On bare, polished metals, the absorptivity of the $10.6 \mu \mathrm{m}$ radiation from a $\mathrm{CO}_{2}$ laser is on the order of $10 \%$ for irradiances less than $10^{5} \mathrm{~W} / \mathrm{cm}^{2}$. The absorptivity of $1.06 \mu \mathrm{m}$ radiation from a Nd:YAG laser for bare polished metals is 35-45\%.[3] Since transformation surface hardening requires a controlled heating of the materials, enough to cause a phase transformation without melting the surface, much lower irradiances, on the order of $10^{3}$ to $10^{4}$ $\mathrm{W} / \mathrm{cm}^{2}$ are used.[4] In order to get reasonable coupling between the laser and the metal, some coating is generally required which adds the cost to the process. Since bare metals absorb the more energetic $1.06 \mu \mathrm{m}$ photons much more readily than the $10.6 \mu \mathrm{m}$ photons, there is the possibility of surface hardening without coatings. In this study, surface hardening without coatings was applied 
to two ferrous materials, 1045 steel and gray cast iron (3.10-3.50 wt\% carbon content). The tests were carried out with an available high power pulsed Nd:YAG laser that adequately approximated a $\mathrm{CW}$ effect. The results of the heat treatment, such as range of processing parameters and the resulted hardness, case depth and microstructure of the treated layers were presented. Also in this study, an infrared processing monitor was used to monitor in real-time the infrared emissions during laser surface hardening. The signal from the monitor was correlated with the hardness of the laser-treated tracks. Thermal distortion was also characterized by the term of flatness change of the treated surface.

\section{EXPERIMENTAL PROCEDURES}

A pulsed $1.6 \mathrm{~kW} \mathrm{Nd:YAG} \mathrm{laser} \mathrm{(Elctrox)} \mathrm{with} \mathrm{fiber} \mathrm{optic} \mathrm{beam} \mathrm{delivery} \mathrm{through} \mathrm{a} 1000$ $\mu \mathrm{m}$ step-index fiber and a highly astigmatic combination of the $127 \mathrm{~mm}$ cylindrical lens and a 75 $\mathrm{mm}$ spherical lens were used to conduct the surface hardening treatment. This lens combination is shown in Figure 1. An oval beam profile was achieved by the combined lens. The oval beam profile was chosen because of the aspect ratio and the steepness of the irradiance gradient along the minor axis (the beam was translated parallel to the major axis) which minimized waste of energy. The treated tracks were made on 1045 steel and gray cast iron (3.10-3.50 wt\% carbon content) at dbeam travel speeds ranging from 1 to $5 \mathrm{~cm} / \mathrm{s}$ provided by moving the workpiece on a CNC stage

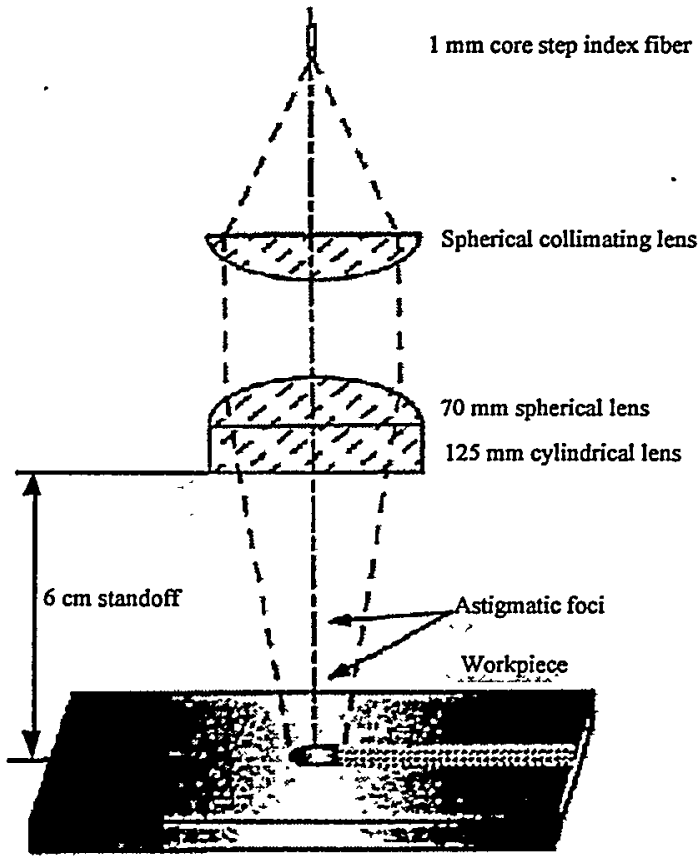

Figure 1 Layout of lenses used for heat treatment with Nd:YAG system

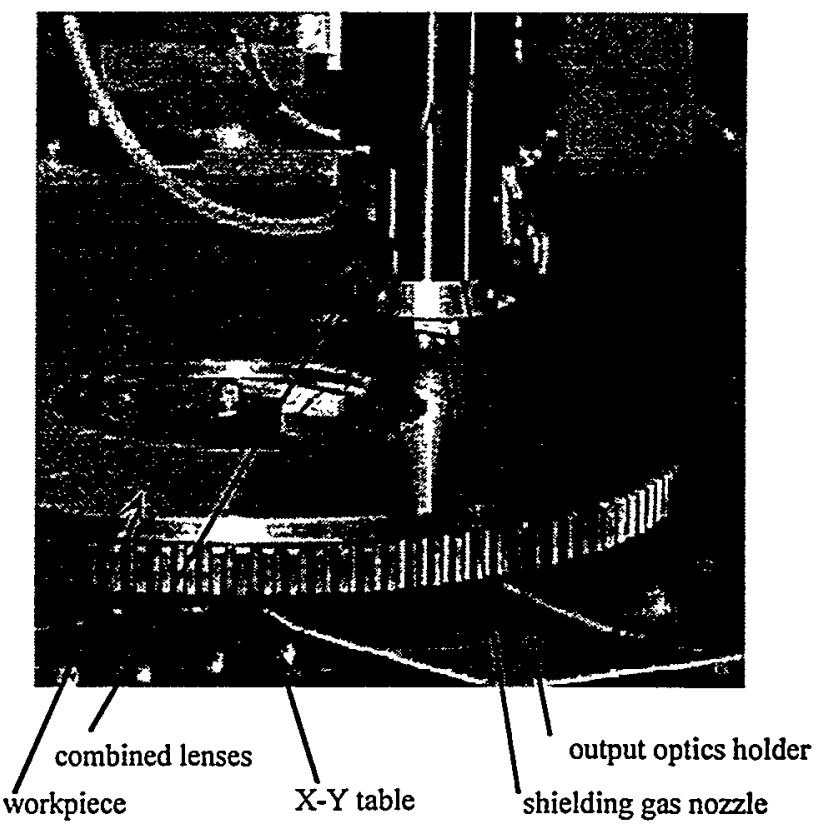

Figure 2 Annotated photograph of Nd:YAG laser surface hardening

under the stationary laser head. The average power was 1200 watts ( $3.0 \mathrm{~kW}$ peak power) at the workpiece, in which the pulse width was $2 \mathrm{~ms}$ and the repetition rate was $200 \mathrm{~Hz}$. The pulse parameters were set to simulate the effect of a cw laser taking into account the thermal relaxation time of the metal. The same pulse settings were used for both alloys. The oval beam, after being defocused, had a minor axis of $4 \mathrm{~mm}$ and major axis of $6 \mathrm{~mm}$. Then the area of the oval beam was $0.75 \mathrm{~cm}^{2}$, giving the peak irradiance of the beam of $3.89 \times 10^{3} \mathrm{~W} / \mathrm{cm}^{2}$. Top gas shielding was provided by a $25 \mathrm{lpm}$ flow of nitrogen in a trailing jet configuration delivered by a $0.8 \mathrm{~cm}$ diameter 
tube oriented at $15^{0}$ from the surface, 450 from the horizontal and $10 \mathrm{~mm}$ from beam spot. The annotated photograph of the set-up of YAG laser surface hardening is shown in Figure 2. An infrared weld monitor, successfully used to monitor the weld quality,$[5,6]$ was utilized to monitor the processing of surface hardening. The monitor was integrated into the YAG beam delivery optics and uses oversized, off-axis optics to collect the infrared emission signal associated with laser beam surface hardening. Monitor voltages as a function of time were collected using data acquisition hardware and software (GW Instruments, Somerville, MA) with an Apple Macintosh computer. The data collection rate was 2500 to $5000 \mathrm{~Hz}$. The Rockwell $\mathrm{C}$ hardnesses along the treated tracks were measured using a portable hardness tester. The corresponding monitor voltage for each hardness measurement on a treated track was obtained from the monitor voltage-time plot. After surface hardening, the treated tracks were sectioned, polished, and etched to determine microstructure, case depth, and width. The deviation of the flatness after the treatment was measured using a Starrett's dial indicator with a accuracy of 0.001 ".

\section{RESULTS AND DISCUSSION}

The microstructures of laser treated and untreated 1045 steel are shown in Figure 3. There are a completed hardened zone and a transition zone in the laser treated case (Fig. 3 (a)). Ferrite phase on the original pearlite boundaries remained in the transition zone because of the temperature distribution along the case depth as shown in Figure 4. When the material temperature was larger than $\mathrm{A}_{\mathrm{c} 3}$, all the phases at room temperature transformed into austenite. After the self-quenching, the austenite transformed into martensite. At temperatures in the range between $A_{c 1}$ and $A_{c 3}$, a part of ferrite phase still remained besides the austenite phase. After self-quenching, the ferrite phase

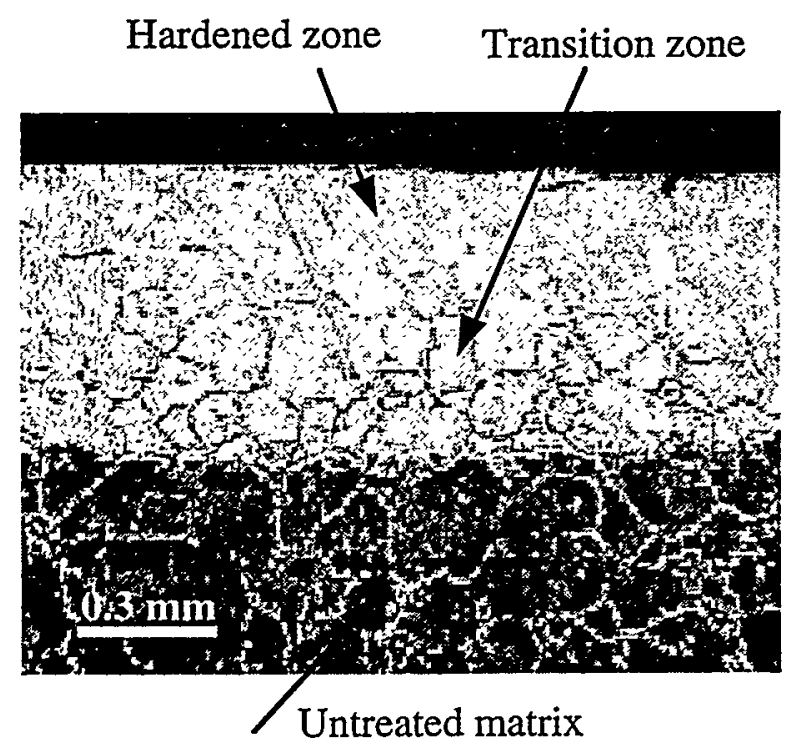

(a)

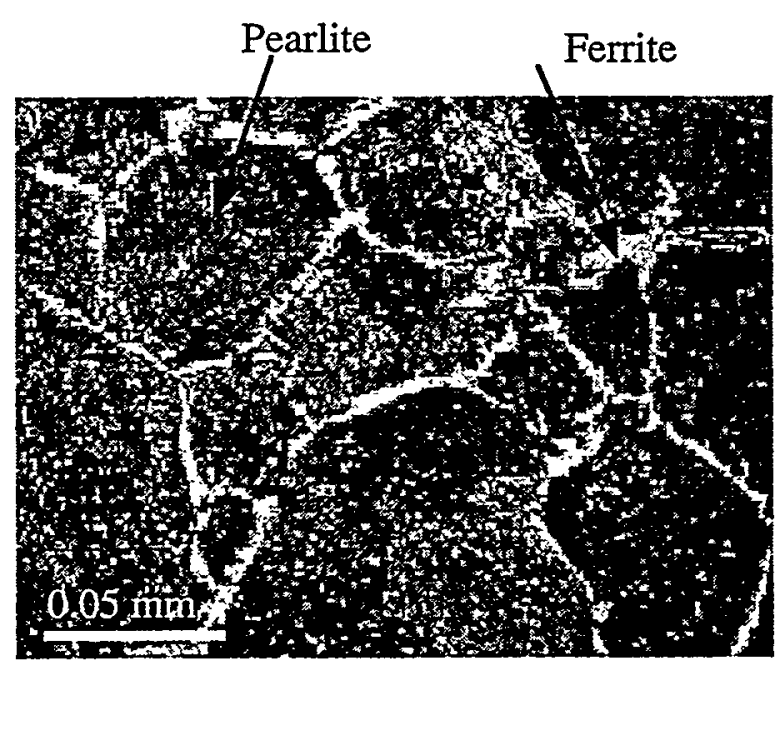

(b)

Figure 3 Micrographs of laser surface hardening of 1045 steel for beam power $1200 \mathrm{~W}$, pulse width $2 \mathrm{~ms}$, pulse frequency $200 \mathrm{~Hz}$ and beam travel speed of $2 \mathrm{~cm} / \mathrm{s}$. (a) $50 \mathrm{X}$ and (b) untreated zone at $400 \mathrm{X}$. 


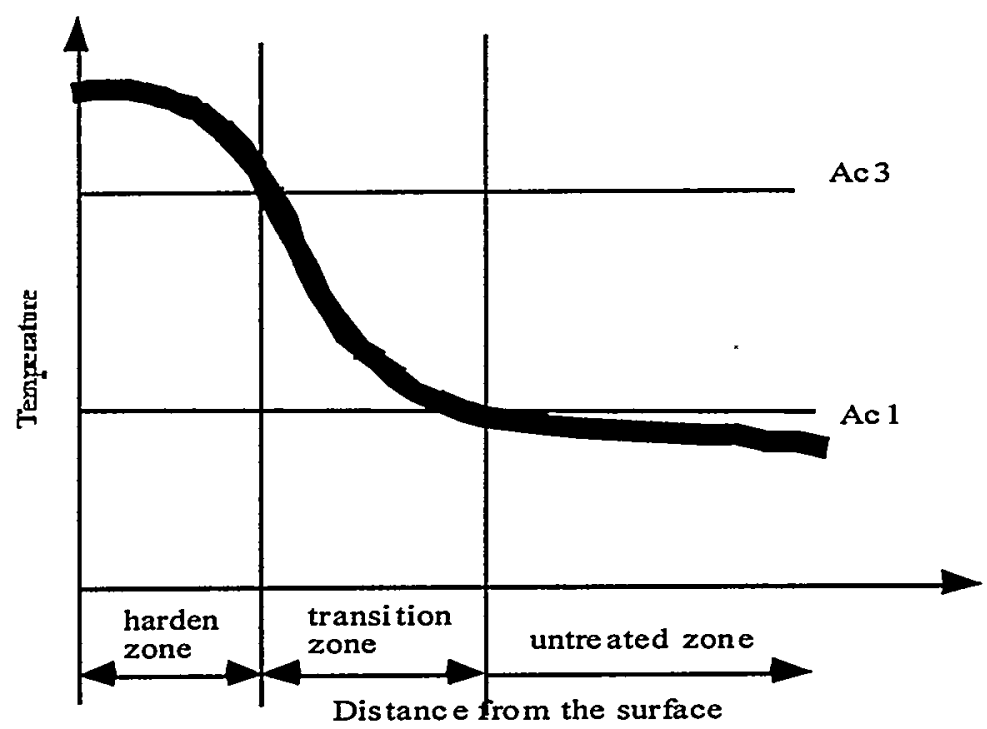

Figure 4. Schematic of temperature distribution versus distance from the workpiece surface.

remained. Below $A_{c 1,}$, there is no phase transformation. The typical annealed microstructure of pearlite (black phase) plus ferrite (white phase) was observed for untreated matrix (Fig. 3 (b)). Since the temperature distribution changes with beam travel speed, the case depth changes. As the beam travel speed increased at fixed beam power, the case dpeth decreased. So did the thickness of

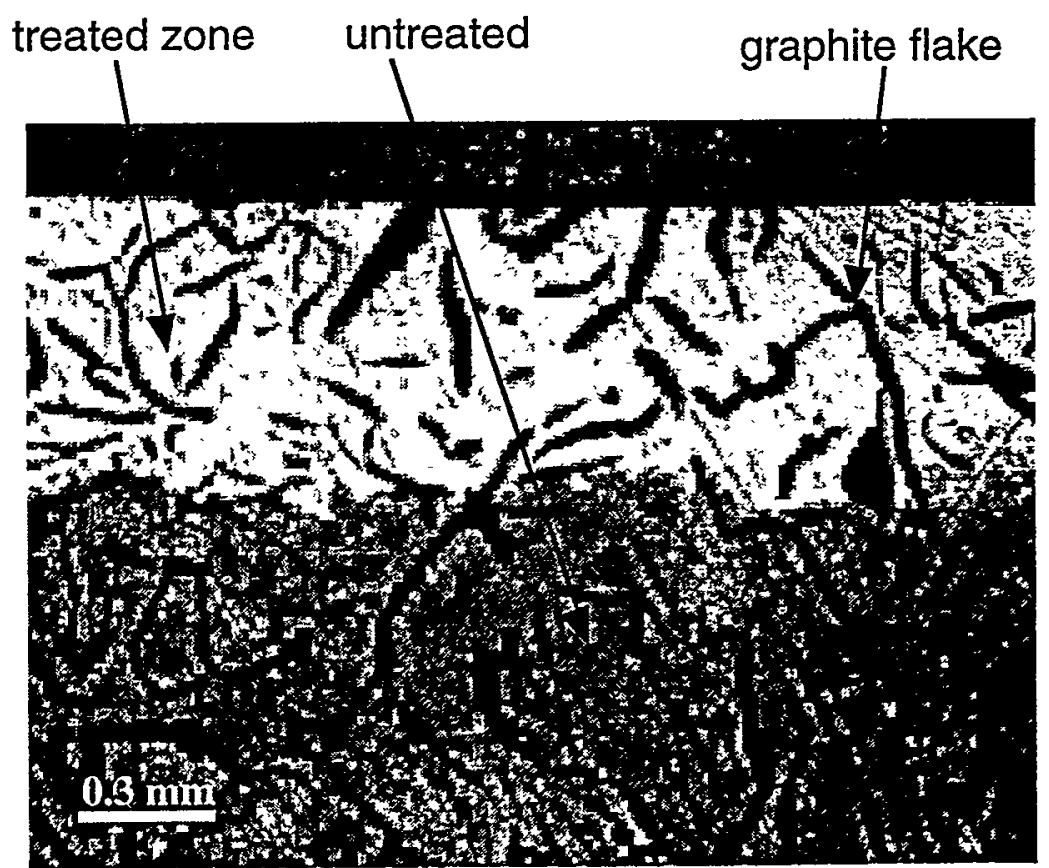

Figure 5 Micrograph showing laser treated surface layer (white) and untreated matrix. 
the transition zone. Figure 5 shows the microstructures after laser surface hardening of gray cast iron. The graphite flakes kept unchanged. The hardness for laser treated gray cast iron and 1045 steel at varied beam travel speeds are shown in Figure 6. The beam travel speeds for surface melting were indicated by the vertical lines below which the surface melting occurred. The maximum hardness possible without surface melting for 1045 was HRC 61 and HRC 40 for gray cast iron. The gray cast iron is more difficult to harden without surface melting because of its lower melting point $(1154 \mathrm{O})$ and a significantly longer time-at-temperature required to diffuse carbon atoms from the graphite flakes into the matrix during laser heating, $[7,8,9]$ Since the pulse frequency was set to mimic $\mathrm{CW}$ operation and the beam was scanned over the workpiece surface, the interaction time between the beam and workpiece can be expressed as:[10]

$$
\text { Interaction Time }=\frac{\text { Beam length in beam travel direction }}{\text { Beam travel speed }}
$$

Therefore, the interaction time was in the range of 0.12 to 0.60 seconds for beam travel speed of 5 $\mathrm{cm} / \mathrm{s}$ to $1 \mathrm{~cm} / \mathrm{s}$ with a beam length in beam travel direction of $6 \mathrm{~mm}$. For gray cast iron, this short

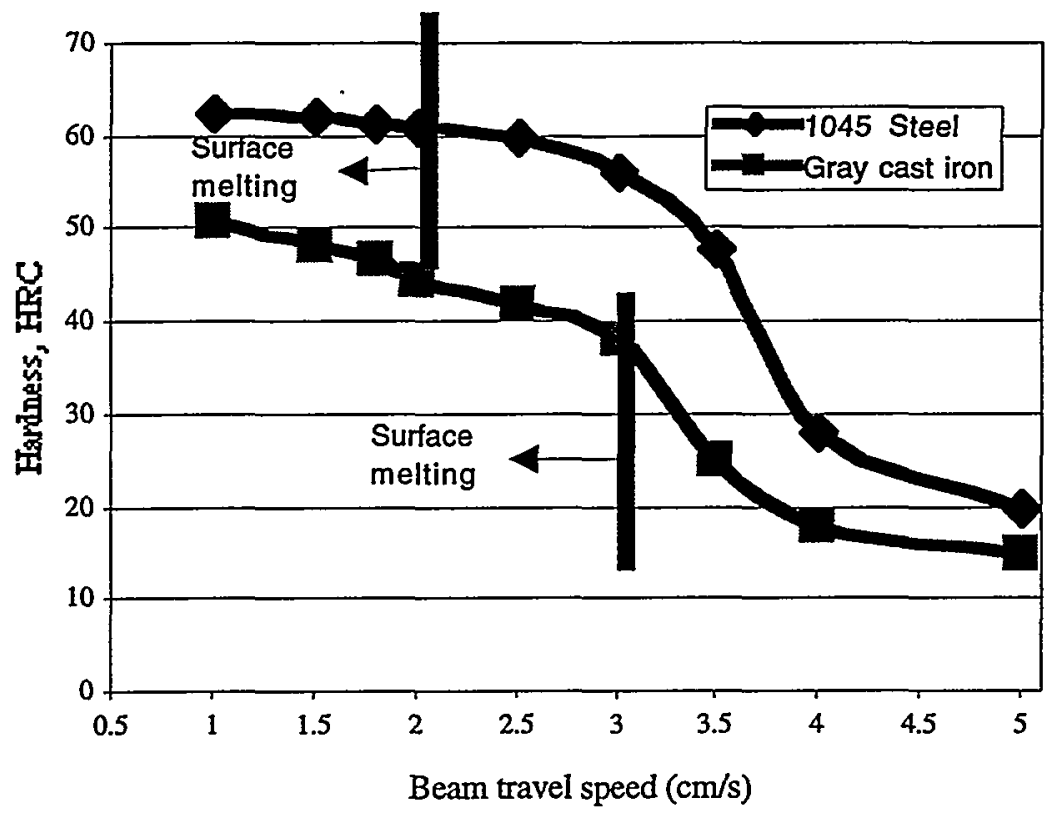

Figure 6 Hardness at varied beam travel speeds on 1045 steel and gray cast iron for $1200 \mathrm{~W}$ of Nd:YAG.

austenitizing cycle time can not provide enough time-at-temperature to form a homogeneous austenite containing all available carbon so that the hardest possible martensite would form upon cooling. On the other hand, 1045 steel has a higher melting temperature, $14600^{\circ} \mathrm{C}$. The higher the austenitizing temperature, the longer the time that laser can heat the certain volume of material without surface melting, the shorter the time-at-temperature required to diffuse certain amount of carbon atoms and the more available carbon in the austenite phase. Therefore, 1045 steel can harden to higher hardness level (HRC 61) compared to gray cast iron at the same beam travel speed $(2.5 \mathrm{~cm} / \mathrm{s})$ and beam parameters. The typical case depth profiles hardened at beam travel speed of $2.5 \mathrm{~cm} / \mathrm{s}$ on a 1045 steel and gray cast iron are shown in Figure 7. The longitudinal hardness 
profile and transverse hardness profile hardened at beam travel speed of $2.5 \mathrm{~cm} / \mathrm{s}$ on a 1045 steel plate are shown in Figure 8 and 9. A case depth of $0.6 \mathrm{~mm}$ with hardness of HRC 61 for 1045 steel and HRC 40 for gray cast iron was obtained. Longitudinal and transverse hardness profile show that very uniform hardness obtained on the treated track indicating the good quality of the beam achieved through the special optics. The deviations measured on a gray cast iron component before and after laser surface treatment at $2.5 \mathrm{~cm} / \mathrm{s}$ are shown in Figure 10. The thermal distortion due to the laser surface hardening was less than $16 \mu \mathrm{m}$, which is much less than the limitation of thermal distortion required for fitup of parts.

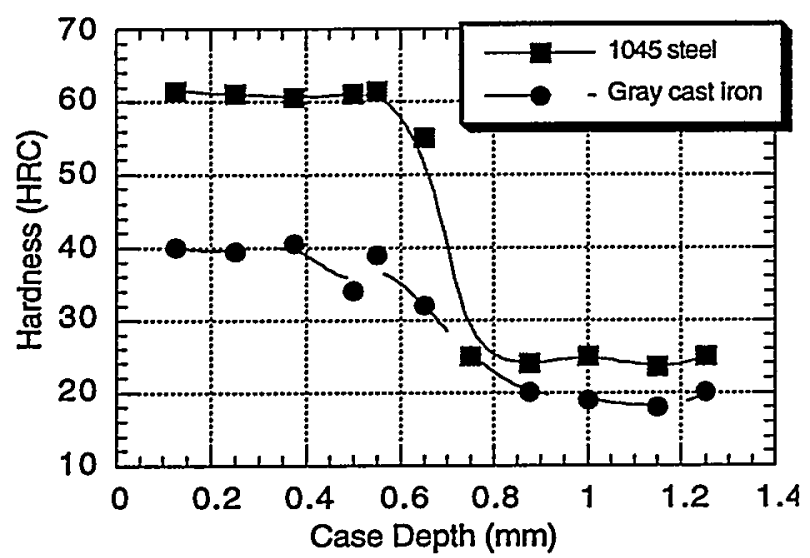

Figure 7 Case depth for $1200 \mathrm{~W}$ of Nd:YAG hardened at $2.5 \mathrm{~cm} / \mathrm{s}$ on 1045 steel and gray cast iron plates

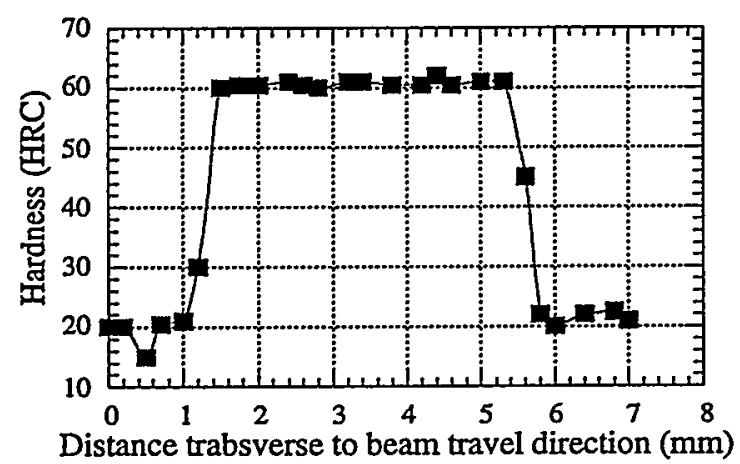

Figure 9 Transverse hardness profile for 1200 $\mathrm{W}$ of Nd:YAG at $2.5 \mathrm{~cm} / \mathrm{s}$ on 1045 steel plate.

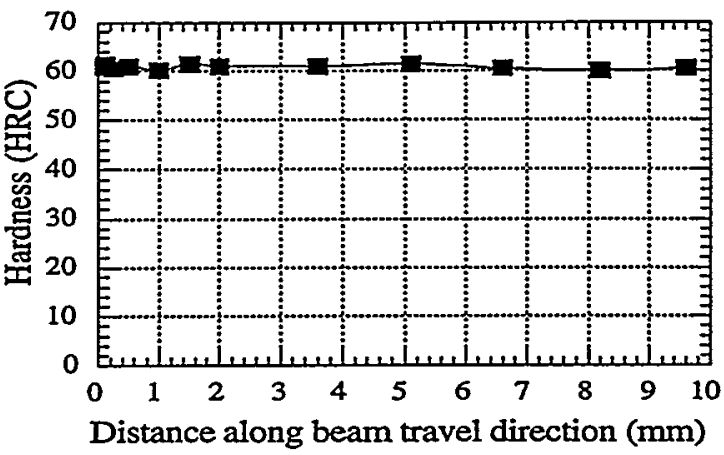

Figure 8 Longitudinal hardness profile for $1200 \mathrm{~W}$ of $\mathrm{Nd}: \mathrm{YAG}$ at $2.5 \mathrm{~cm} / \mathrm{s}$ on 1045 steel plate.

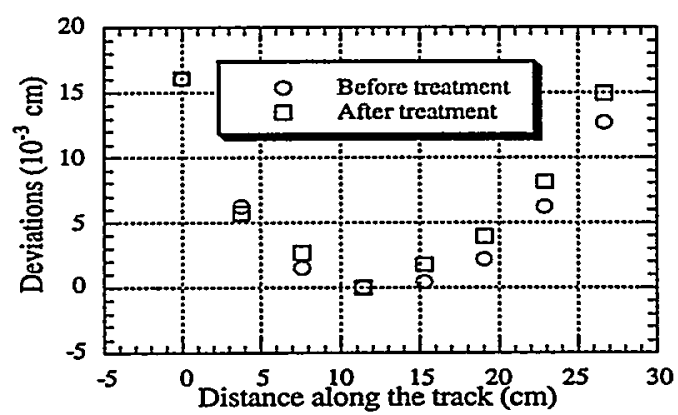

Figure 10 Deviations measured along the laser-treated track on a gray cast iron component before and after the treatment at a beam travel speed of $2.5 \mathrm{~cm} / \mathrm{s}$.

\section{CONCLUSIONS}

Nd:YAG laser can be used efficiently to laser-harden uncoated 1045 steel and partially harden gray cast iron without surface melting. The beam travel speed for surface melting was found to be $2 \mathrm{~cm} / \mathrm{s}$ for 1045 steel and $3 \mathrm{~cm} / \mathrm{s}$ for gray cast iron for a laser beam power of 1200 watts. Case depth of $0.6 \mathrm{~mm}$ with Rockwell $\mathrm{C} 61$ and 40 were achieved without surface melting for laser-treated 1045 steel and gray cast iron respectively. 


\section{ACKNOWLEDGMENTS}

This work was funded by the U.S. Department of Energy, Office of Energy Research Laboratory Technology Research Program and the Office of Transportation Technologies.

\section{REFERENCES}

1. S. Lampman, "Introduction to surface hardening of steels," ASM Handbook, Vol. 4, Heat Treating, ASM International, Materials Park, OH. 1997, pp. 259-267.

2. T. Ruglic, "Flame hardening," ASM Handbook, Vol. 4, Heat Treating, ASM International, Materials Park, OH. 1997, pp. 268-285.

3. C. J. Nonhof, "Material processing with Nd lasers," Electrochemical Publications, Ayr, Scotland, 1988, pp. 150-154.

4. W. M. Steen, "Laser Material processing," Springer-Verlag London Limited 1991.

5. K. H. Leong, "Low cost laser weld monitoring system," Proceedings of the Automotive Laser Applications Workshop, 1997, Novi, MI., 4-5 March, 1997.

6. P.G. Sanders, K. H. Leong, J. S. Keske, and G. Korneck, "Real-time monitoring of laser beam welding using infrared weld emissions," J. Laser Appl., Vol. 10, No., 5, October 1998.

7. V. G. Gregson, "Laser heat treatment," Chap. 4, Materials Processing, edited by M. Bass, Holland Publishing Company, 1983.

8. O. A. Sandven, "Laser surface hardening," ASM Handbook, Vol. 4, Heat Treating, ASM International, Materials Park, OH. 1997, pp. 286-296.

9. P. J. Oakley, "Review of laser heat treatment and surface techniques," Research report, The Welding Institute, November, 1980.

10. F. D. Seaman, "Laser heat-treating," Industrial Laser Handbook, 1995. 